\title{
Asthma and atopy: endocrine or metabolic conditions?
}

\section{Forbes}

\section{New perspectives on the relationship between asthma or allergy and female sex hormones}

$\mathrm{F}$ emale sex hormones seem to have something to do with asthma and allergy. You might think this is a bit vague, but the research on this so far doesn't merit anything stronger. Women of reproductive age are more likely to be admitted to hospital for asthma than men. ${ }^{1}$ Intrigued by this, people have studied the link between asthma or allergy and markers of female sex hormone levels-for example, time of menstrual cycle, menopause, pregnancy, hormonal contraceptives, hormone replacement therapy, maternal parity, and age at menarche-but the overall picture remains confused. The results of the studies are inconsistent, with no unifying pattern of effects of hormones. Three recent studies in Thorax, two in this issue ${ }^{23}$ and one published in June this year, ${ }^{4}$ have added some new pieces to the jigsaw puzzle and a new perspective on the problem.

Brenner et $a l^{2}$ looked at menstrual variation in asthma symptoms. We have recognised for a long time that some women get worse asthma symptoms at certain times of the month. Surveys of asthma outpatient clinics suggest that about a third of women experience worse symptoms just before and during their periods, ${ }^{5-7}$ although the figure would probably be lower in community based surveys. A few researchers have shown that peak expiratory flows ${ }^{5}$ or bronchial responsiveness ${ }^{8}$ vary over the menstrual cycle, but others have shown no such variation. ${ }^{90}$ As with the premenstrual syndrome, exactly what it is about the different phases of the menstrual cycle that might exacerbate asthma is not known. Could it be absolute levels of oestrogens or progesterone, relative levels, changes in levels, or something else altogether? In the absence of an answer from looking at oestrogen and progesterone levels, research into the pathophysiology of the premenstrual syndrome has looked at other endocrine systems: reninangiotensin-aldosterone, 5-hydroxytryptamine and gamma aminobutyric acid, among others. ${ }^{11}$
The study by Brenner et al thickens the plot further: in 800 women (all premenopausal and not taking the contraceptive pill) attending the emergency room for asthma, more attended just before or during their periods (as expected), but a high proportion also attended just before they ovulated. The differences were fairly small: $27 \%$ attended during days 26 to 4 and $28 \%$ during days 5 to 11 , compared with $25 \%$ during days 12 to 18 and $21 \%$ during days 19 to 25 . A preovulatory increase in asthma emergency attendances has been noted before in a smaller study of 288 women, in which 33\% attended during days 5 to 11 and only $21 \%$ during days 26 to $4 .{ }^{12}$ In terms of gonadal hormone levels, the perimenstrual phase of the menstrual cycle is broadly characterised by fairly low levels of oestradiol and progesterone and the preovulatory phase by rising levels of oestradiol.

This line of enquiry is interesting not just because of the therapeutic implications for women with asthma that varies over the menstrual cycle, but because of the clues it leaves about the aetiology of asthma. Aetiology was the focus of the two other studies. Maitra et $a^{3}$ examined associations between maternal age at menarche (early menarche being a marker of higher oestrogen levels in adulthood) and asthma and atopy in offspring, the hypothesis being that oestrogen exposure in utero might influence the later development of these conditions. An analysis of data from the Avon Longitudinal Study of Parents and Children, it found no association between maternal age at menarche and asthma (based on parental questionnaire responses) or atopy (based on parental questionnaire responses and positive skin prick tests to common aeroallergens) at age 7 . This conflicts with the findings of an analysis of a Finnish birth cohort which found that maternal late menarche was associated with a lower prevalence of atopy at age 31, but there was no association between later menarche in the birth cohort members themselves and atopy at age 31 , nor any association between maternal age at menarche and asthma. ${ }^{13}$

The study by Svanes et al ${ }^{4}$ published in the June issue of Thorax examined the association between irregular menstruation and asthma and atopy in women. A community based postal questionnaire survey of over 8000 Northern European women aged 25-42 found that women with irregular periods were about 50\% more likely to have asthma or asthma symptoms and about 30\% more likely to report hay fever than those who said they had regular periods. The increase in risk was not explained by asthma medication, which may influence levels of sex hormones. ${ }^{14}$

This is a new and interesting finding. The association was strong and fairly consistent across the different participating countries. The women were young, so menopause is unlikely to explain it, and it is unlikely that breastfeeding is common enough at any one time to have any effect. One of the difficulties of interpreting the association is that women with irregular periods may attend for health care advice more often, so may be more likely to have received a diagnosis of asthma or hay fever; however, in the study, irregular menstruation was also associated with symptoms of asthma. Another difficulty is that women with "irregular menstruation" were defined as premenopausal (that is, had had a period in the last 6 months), were nonpregnant and not taking oral contraceptives or hormone replacement therapy, and had answered "no" to the question: "Do you have regular menstrual periods?", the assumption being that this meant that they had irregular periods-probably reasonable, but that wasn't quite what the question asked.

The authors offer two hypotheses to explain the association. The first is that the disturbance of sex hormones associated with irregular menstruation might cause asthma. What that disturbance might be is not clear. Women have irregular periods for a variety of reasons: for several months after stopping hormonal contraceptives or breastfeeding, injected or intrauterine contraceptives, eating disorders, weight gain, hard sports training, psychological disturbance, fibroids, endometriosis, and endocrine disorders including polycystic ovary syndrome, diabetes and thyroid disease. To my knowledge there is no known pattern of sex hormone disturbance common to all these.

The second hypothesis is more interesting and offers a much needed new perspective on the relationship between female sex hormones and asthma and, indeed, the aetiology of asthma. 
Polycystic ovary syndrome, probably the most common endocrine cause of irregular menstruation and the most common form of anovulatory infertility, ${ }^{15}$ is associated with insulin resistance which, like the metabolic syndrome, is a strong risk factor for cardiovascular disease. $^{16}$ The authors suggest that asthma, allergy, and menstrual irregularity caused by polycystic ovary syndrome may have insulin resistance in common. This might fit in with the as yet unexplained association between asthma and obesity, which is particularly strong in women, ${ }^{17}$ and between lung function and insulin resistance. ${ }^{18}$ Could asthma be another manifestation of the metabolic syndrome? Could something in early life influence the development of asthma, allergy, and insulin resistance?

Women with polycystic ovary syndrome have high circulating levels of androgens, polycystic ovaries on ultrasound imaging, oligo- or anovulatory cycles and, usually, oligo- or amenorrhoea. ${ }^{19}$ The precise diagnostic criteria are considered contentious, although the prevalence is estimated to be as high as $5-10 \%$ of women of reproductive age. ${ }^{20}$ Are these women more likely to have asthma or atopy? Women with infertility were more likely to have used asthma medication before age 21 in a case-control study. ${ }^{21}$

These studies add more chapters to the rather jumbled story of female sex hormones and asthma and allergy. The hypothesis put forward by Svanes and colleagues-that asthma and allergy share a common aetiology with metabolic syndrome which may be related to early life influences on insulin resistance-is attractive, suggesting a new metabolic line of enquiry for researchers trying to identify the causes of asthma. It may also help identify what female sex hormones have to do with asthmaif anything.

Thorax 2005;60:793-794.

doi: $10.1136 /$ thx.2005.047050

Correspondence to: Dr L Forbes, Consultant in Public Health Medicine, Wandsworth Primary Care Trust, Lupin Ward, Jasmine Tower, Springfield Hospital, 61 Glenburnie Road, London SW17 7DJ, UK; Lindsay.forbes@ swlondon.nhs.uk

\section{REFERENCES}

1 Skobeloff EM, Spivey WH, St Clair SS, et al. The influence of age and sex on asthma admissions. JAMA 1992;268:3437-40

2 Brenner BE, Holmes TM, Mazal, et al. Relation between phase of the menstrual cycle and asthma presentations in the emergency department. Thorax 2005;60:806-9.

3 Maitra A, Sherriff A, Northstone K, et al. Maternal age of menarche is not associatied with asthma or atopy in prepubertal children. Thorax 2005;60:810-3

4 Svanes C, Real FG, Gislason T, et al. Association of asthma and hay fever with irregular menstruation. Thorax 2005:60:445-50.

5 Hanley SP. Asthma variation with menstruation. Br J Dis Chest 1981;75:306-8.

6 Gibbs CJ, Coutts II, Lock R, et al. Premenstrual exacerbation of asthma. Thorax 1984;39:833-6.

7 Rees L. An aetiological study of premenstrual asthma. J Psychosom Res 1963;7:191-7.

8 Tan KS, McFarlane LC, Lipworth BJ. Loss of normal cyclical beta 2 adrenoceptor regulation and increased premenstrual responsiveness to adenosine monophosphate in stable female asthmatic patients. Thorax 1997; 52:608-11.

9 Weinmann GG, Zacur H, Fish JE. Absence of changes in airway responsiveness during the menstrual cycle. J Allergy Clin Immunol 1987;79:634-8

10 Juniper EF, Kline PA, Roberts RS, et al. Airway responsiveness to methacholine during the natural menstrual cycle and the effect of oral contraceptives. Am Rev Respir Dis 1987; 135: 1039-42.

11 Halbreich U. The etiology, biology, and evolving pathology of premenstrual syndromes. Psychoneuroendocrinology 2003;28:55-99

12 Zimmerman JL, Woodruff PG, Clark S, et al. Relation between phase of menstrual cycle and emergency department visits for acute asthma. Am J Respir Crit Care Med 2000; 162:512-5.

13 Xu B, Jarvelin MR, Hartikainen AL, Pekkanen J. Maternal age at menarche and atopy among offspring at the age of 31 years. Thorax 2000;55:691-3.

14 Kos-Kudla B, Ostrowska Z, Marek B, et al. Hormone replacement therapy in postmenopausal asthmatic women. J Clin Pharm Ther 2000;25:461-6.

15 Franks S. Polycystic ovary syndrome. NEngl J Med 1995;333:853-61.

16 Taylor AE. Understanding the underlying metabolic abnormalities of polycystic ovary syndrome and their implications. Am J Obstet Gynecol 1998;179:S94-100.

17 Weiss ST, Shore S. Obesity and asthma: directions for research. Am J Respir Crit Care Med 2004; 169:963-8.

18 Lawlor DA, Ebrahim S, Smith GD. Associations of measures of lung function with insulin resistance and type 2 diabetes: findings from the British Women's Heart and Health Study. Diabetologia 2004;47:195-203.

19 Ehrmann DA. Polycystic ovary syndrome. N Engl J Med 2005;352:1223-3.

20 Hopkinson ZE, Sattar N, Fleming R, et al. Polycystic ovarian syndrome: the metabolic syndrome comes to gynaecology. BMJ 1998;317:329-32.

21 Grodstein F, Goldman MB, Ryan L, et al. Self reported use of pharmaceuticals and primary ovulatory infertility. Epidemiology 1993;4:151-6.

\section{Passive smoking and asthma exacerbation}

\section{J Britton}

\section{Further evidence to advance the public, political, and legal process towards effective public protection from the effects of passive and active smoking}

${ }^{i}$ garette smoke is a toxic mixture containing around 4000 different chemicals including a range of carcinogens, irritants, and toxins. ${ }^{1}$ It is therefore no surprise that inhaling cigarette smoke, either actively as a cigarette smoker or passively through exposure to exhaled and sidestream smoke from other smokers, is bad for health. ${ }^{1}$ In fact, active smoking kills more people in economically developed countries than any other preventable cause, and currently accounts for over 100000 deaths (or about 20\% of all deaths) each year in the UK. ${ }^{2}$ Worldwide the annual death total is currently close to 5 million. ${ }^{3}$ Passive smoking is also a major problem, causing at least 12000 deaths each year in the $\mathrm{UK}^{4}$ or about $2 \%$ of the current annual total, and probably a similar proportion in other developed countries. On these figures alone it should be clear that we have sufficient evidence to conclude that preventing exposure to cigarette smoke, either active or passive, should be a fundamental priority of all clinical and public health practice. We already know what the main health effects of smoking are, or in relation to passive smoking, are likely to be. So do we need more research defining the adverse effects of passive smoking in still greater detail?

The answer to this question is that we do, and primarily to inform, support, or otherwise enhance the political process towards effective tobacco control. While governments continue to prevaricate over the implementation of simple public health measures to reduce smoking incidence and encourage smoking cessation, new evidence can help tobacco control lobbyists and supporters both inside and outside the government and health services to press for change. New 
evidence is helpful in keeping the media interest in a topic alive and thus maintaining pressure on policy makers to act. In parallel to the political process, much that is good for public health can come from decisions made in courts of law. If the emergence of new evidence on tobacco effects were to contribute to successful legal claims for injury arising from tobacco smoke exposure, for example at work, that would also probably have a major impact on the measures employers deem necessary to take to protect employees from passive smoke exposure. New evidence therefore matters but, to be useful, it should ideally be strong enough to contribute to the above processes.

In this issue of Thorax Eisner and colleagues report new data suggesting that passive smoking exacerbates asthma. ${ }^{5}$ There is already an extensive literature, reviewed elsewhere, showing that passive smoking is associated with an increased risk of asthma in children and adults, ${ }^{16-8}$ and observational evidence (including other work by Eisner et al) that passive smoke exposure exacerbates symptoms in people with asthma. ${ }^{9-14}$ These latter findings are supported by the results of experimental challenge studies indicating that passive smoke exposure has adverse effects on airflow and/or airway responsiveness in asthma. ${ }^{15-19}$ Collectively, therefore, the existing evidence provides strong grounds to suspect that passive smoke exposure is bad for asthma. What this new study argues is that the existing epidemiological data are based predominantly on self-reported passive smoke exposure, and as such may be biased, and instead uses personal nicotine monitoring and hair nicotine and cotinine assays to provide objective measures of passive smoke exposure in a cohort of patients recently discharged from hospital with acute asthma.

The study concludes that people in the highest tertile of personal exposure to nicotine have more severe asthma, while those with higher levels of hair nicotine in the past month had a higher risk of hospitalisation for asthma between the index (recruitment) admission and the time of hair sampling (referred to as "baseline risk"). There were other potentially significant findings in the several hypothesis tests carried out across three levels of exposure for five exposure measures and five outcomes presented in tables 5 and 6 of the paper, and the overall pattern of the findings on the relation to symptom scores is consistent with the interpretation that individuals with higher levels of passive smoke exposure had more troublesome asthma. The findings on the risk of hospitalisation were perhaps less convincing.
Participation in the study was low, since only $53 \%$ of those eligible for inclusion completed an initial telephone interview and less than $25 \%$ of those who completed the interview (that is, under $12.5 \%$ of the original proposed study population) participated in the exposure measures. The representativeness of this participant population in relation to any association between passive smoking and asthma exacerbation is therefore questionable. By virtue of its observational design, the study is also unable to determine whether the relation between passive smoke exposure and asthma severity is causal or is confounded by other factors. For example, asthma severity is strongly dependent on adherence to appropriate treatment, but access to and use of treatment may be lower in relatively deprived individuals who are also more likely to be smokers or to mix with other smokers both socially and at work. ${ }^{20}$ The authors have used level of education to control for socioeconomic status but this may be insufficient to deal with this problem. The individual personal smoking status of participants does not appear to have been validated; only current non-smokers were included in the study, but smoking status appears to be based on self-report. Objective measures of serum, salivary, or urinary cotinine levels and/or exhaled carbon monoxide would have been helpful to validate these reports. These and other criticisms mean that, while the study concludes what many with an interest in this area would like or believe to be true, the main findings could still be due to chance or bias.

On the other hand, previous studies using objective markers of passive smoking in children have produced strong evidence that higher levels of exposure are associated with more severe asthma, ${ }^{21-23}$ and the experimental challenge data cited above ${ }^{15-19}$ provide support for the hypothesis that this is also likely to be true in adults. It is therefore reasonable to conclude that passive smoke exposure is likely to be bad for all people with asthma who would be well advised to avoid exposure, as indeed is the case for everyone else. Whether this latest addition to the evidence base represents an important step in terms of advancing the public, political, and legal process towards effective public protection from the effects of passive and active smoking remains to be seen.

Thorax 2005;60:794-795.

doi: $10.1136 /$ thx.2005.045336

Correspondence to: Professor J Britton, University of Notttingham, Division of Epidemiology and Public Health, Clinical Sciences Building, City Hospital, Nottingham NG5 1PB, UK; i.britton@virgin.net

\section{REFERENCES}

1 Royal College of Physicians. Going smoke-free: the medical case for clean air in the home, at work and in public places, A report on passive smoking by the Tobacco Advisory Group of the Royal College of Physicians. London: Royal College of Physicians, 2005.

2 Twigg L, Moon G, Walker S. The smoking epidemic in England. London: Health Development Agency, 2004

3 Ezzati M, Lopez AD. Estimates of global mortality attributable to smoking in 2000. Lancet 2003;362:847-52

4 Jamrozik K. Estimate of deaths attributable to passive smoking among UK adults: database analysis. BMJ 2005;330:812-7.

5 Eisner MD, Klein J, Hammond SK, et al. Directly measured second hand smoke exposure and asthma health outcomes. Thorax 2005;60:814-21.

6 Cook DG, Strachan DP. Parental smoking and prevalence of respiratory symptoms and asthma in school age children. Thorax 1997;52:1081-94

7 Strachan DP, Cook DG. Parental smoking and childhood asthma: longitudinal and case-control studies. Thorax 1998;53:204-12.

8 Scientific Committee on Tobacco,

Health (SCOTH). Secondhand smoke: review of evidence since 1998. Update of evidence on health effects of secondhand smoke. London: Department of Health, 2004.

9 Eisner MD, Yelin EH, Henke J, et al. Environmental tobacco smoke and adult asthma: the impact of changing exposure status on health outcomes. Am J Respir Crit Care Med 1998; 158:170-5.

10 Schwartz J, Timonen KL, Pekkanen J. Respiratory effects of environmental tobacco smoke in a panel study of asthmatic and symptomatic children. Am J Respir Crit Care Med 2000;161:802-6.

11 Ulrik CS, Lange P. Cigarette smoking and asthma. Monaldi Arch Chest Dis 2001;56:349-53.

12 Eisner MD, Yelin EH, Katz PP, et al. Exposure to indoor combustion and adult asthma outcomes: environmental tobacco smoke, gas stoves, and woodsmoke. Thorax 2002;57:973-8.

13 Morkjaroenpong V, Rand CS, Butz AM, et al. Environmental tobacco smoke exposure and nocturnal symptoms among inner-city children with asthma. J Allergy Clin Immunol 2002; 110:147-53.

14 Soussan D, Liard R, Zureik $M$, et al. Treatment compliance, passive smoking, and asthma control: a three year cohort study. Arch Dis Child 2003;88:229-33.

15 Dahms TE, Bolin JF, Slavin RG. Effects of bronchial asthma. Chest 1981;5:530-4.

16 Knight A, Breslin $A B$. Passive cigarette smoking and patients with asthma. Med J Aust 1985; 142:194-5.

17 Stankus RP, Menon PK, Rando RJ, et al. Cigarette smoke-sensitive asthma: challenge studies. $J$ Allergy Clin Immunol 1988;82:331-8.

18 Menon P, Rando RJ, Stankus RP, et al. Passive cigarette smoke-challenge studies: increase in bronchial hyperreactivity. J Allergy Clin Immunol 1992;89:560-6.

19 Nowak D, Jorres R, Schmidt A, et al. Effect of 3 hours' passive smoke exposure in the evening on airway tone and responsiveness until next morning. Int Arch Occup Environ Health 1997:69:125-33.

20 Lader D, Goddard L. Smoking-related behaviour and attitudes, 2003. London: Office for National Statistics, 2004.

21 Chilmonczyk BA, Salmun LM, Megathlin KN, et al. Association between exposure to environmental tobacco smoke and exacerbations of asthma in children. N Engl J Med 1993;328: 1665-9.

22 Crombie IK, Wright A, Irvine L, et al. Does passive smoking increase the frequency of health service contacts in children with asthma? Thorax 2001;56:9-12.

23 Mannino DM, Homa DM, Redd SC. Involuntary smoking and asthma severity in children. Data from the Third National Health and Nutrition Examination Survey. Chest 2002;122:409-15. 
Exhaled breath condensate

\section{Cyclo-oxygenase-2 inhibitors and COPD: a bright spot?}

\section{R M Effros, R Casaburi}

\section{Usefulness of exhaled breath condensate for following inflammatory events in the lungs}

B efore the recent publication of reports linking cyclo-oxygenase-2 (COX-2) inhibitors with myocardial infarction, ${ }^{1}$ there was strong evidence that this popular group of analgesics does not have the respiratory complications of non-specific antiinflammatory drugs (NSAIDS). ${ }^{2}$ These side effects of the NSAIDs are relatively common (10-20\% of asthmatics) and potentially very serious. Patients experience increased inflammation of the sinuses, nasal polyposis, and severe and potentially fatal airway obstruction. It was postulated that NSAIDs reduce production of prostaglandins that protect the airways and increase synthesis of cysteinyl leukotrienes such as leukotriene $\mathrm{B}_{4} \quad\left(\mathrm{LTB}_{4}\right)$ which aggravate inflammation. The clinical observation that the COX-2 drugs are safe in this respect suggests that inhibition of the COX-1 enzymes is the culprit. It appears that asthmatics can use these very effective analgesics with relatively little risk of exacerbations.

Regardless of the eventual application or modification of NSAIDs and COX-2 inhibitors, widespread use of these drugs has taught us much about the role of the COX enzymes in the lung and other organs. The study by Montuschi and colleagues ${ }^{3}$ in this issue of Thorax serves two important functions: it supports the role of COX-1 activity in protecting the airways and it highlights the potential usefulness of exhaled breath condensate (EBC) as a simple non-invasive method for following inflammatory events in the lungs and the effect of treatment on these disorders.
EBC samples are collected by cooling expired air and collecting the water which condenses on the surfaces of the collecting device. Although this approach avoids the risks, discomfort, and expense of alternative procedures such as sputum induction, bronchoscopy and bronchial biopsy, it is associated with some rather formidable challenges of its own. Concentrations of all non-volatile solutes, including electrolytes and inflammatory markers, are very low and difficult to measure. This reflects the fact that more than $99.9 \%$ of the EBC is composed of water vapour (a gas) which only becomes a liquid when cooled in the condenser. ${ }^{4}$ Aside from the technical problems associated with measuring low solute concentrations, it cannot be assumed that changes in EBC concentrations provide reliable information regarding events in the airways. Increases in the concentrations of $\mathrm{LTB}_{4}$ after NSAIDs could indicate either an increase in the concentrations in respiratory secretions or simply an increase in the number of respiratory droplets generated in the lungs that were then incorporated in the EBC.

There are two ways to compensate for changes in the dilution of respiratory droplets by water vapour. One approach is to monitor the EBC and plasma concentrations of a dilutional reference indicator such as urea or conductivity (these measurements must be conducted in samples which have been freeze dried to remove $\mathrm{NH}_{4}^{+}$and $\left.\mathrm{HCO}_{3}{ }^{-}\right) .{ }^{4}$ Montuschi et al have used an alternative approach. They have compared the EBC concentrations of a variety of markers and found that NSAIDs increase $\mathrm{LTB}_{4}$ and decrease $\mathrm{PGE}_{2}$ concentrations, a change that could not be attributed to an effect of dilution.

There is one puzzling aspect of this report which remains unexplained. Values of $\mathrm{LTB}_{4}$ in this and a previous study conducted by some of the authors of the present report were about one sixth of the bronchoalveolar lavage (BAL) fluid concentrations in normal subjects and nearly the same as BAL fluid concentrations in the presence of pulmonary inflammation. ${ }^{5}$ Studies with dilutional indicators suggest that EBC concentrations of non-volatile indicators should be about $1 \%$ of those found in BAL fluid samples, which might be below the lower limits of their assays. This discrepancy highlights the importance of developing ultrasensitive assays of inflammatory mediators, and the usefulness of dilutional markers which permit calculation of the absolute rather than the relative concentrations of mediators in the respiratory fluid that lines the airways.

Thorax 2005;60:796.

doi: $10.1136 /$ thx. 2005.046821

\section{Authors' affiliations}

R M Effros, R Casaburi, Harbor-UCLA

Medical Center, Los Angeles, CA, USA

Correspondence to: Dr R M Effros, HarborUCLA Medical Center, Torrance, CA90502-

2064, USA; reffros@labiomed.org

\section{REFERENCES}

1 Hippisley-Cox, Coupland C. Risk of myocardial infarction in patients taking cyclo-oxygenase- 2 inhibitors or conventional non-steroidal antiinflammatory drugs: population based nested case control analysis. BMJ 2005;330: 1-7.

2 Picado C. Aspirin-intolerant asthma: role of cyclooxygenase enzymes. Allergy 2002;37(Suppl 72):58-60.

3 Montuschi P, Macagno F, Parente $P$, et al. Effects of cyclo-oxygenase inhibition on exhaled eicosanoids in patients with COPD. Thorax 2005;60:827-33.

4 Effros RM, Biller J, Foss B, et al. A simple method for estimating respiratory solute dilution in exhaled breath condensates. Am J Respir Crit Care Med 2003;168:1500-5.

5 Moloney ED, Mumby SE, Gajocsi R, et al. Exhaled breath condensate detects markers of pulmonary inflammation after cardiothoracic surgery. Am J Respir Crit Care Med 2004; 169:64-9. 
Hypoxaemia and COPD

\section{Hypoxaemia enhanced peripheral muscle oxidative stress in COPD}

\section{Flück}

\section{New findings on the biological defects underlying oxidative damage in patients with COPD}

$C^{2}$ hronic bronchitis and pulmonary emphysema, also know as chronic obstructive pulmonary disease (COPD), is the only leading cause of death with a rising prevalence. ${ }^{1}$ Typically, the reduced lung function of COPD patients is associated with a general deconditioning of muscle function and the consequent development of a sedentary lifestyle. ${ }^{2}$ There is clear evidence that pulmonary rehabilitation programmes that involve generic physical exercise training can improve exercise capacity and state of health in patients with COPD, ${ }^{3}$ so outpatient and home based exercise training are part of the rehabilitation programme for these subjects in Western countries. ${ }^{4}$

The role of co-factors such as hypoxia and inflammation on the health of COPD patients and the resulting improvements of exercise performance with training are poorly understood, but the paper by Koechlin and colleagues ${ }^{5}$ in this issue of Thorax shows that exercise performance and peripheral muscle defects in patients with COPD relate to the level of arterial oxygenation. Using biochemical measures, the authors found that COPD patients with hypoxaemia had higher basal and resistance exercise induced levels of oxidatively damaged lipids and proteins in the vastus lateralis muscle than non-hypoxaemic patients. At baseline, the muscles of hypoxaemic COPD patients also had more lipofuscin inclusions in the muscle fibres and higher neutrophil numbers in the quadriceps muscle. These results suggest that adequate muscle oxygenation is critical to preventing the accumulation of wasteful oxidised lipid products and the harmful downstream reactions that are potentially associated with muscle wasting. ${ }^{6-8}$ Correlation analysis of endurance and arterial oxygen pressure in COPD patients also suggested that blood oxygenation might predict muscle (dys)function. These observations provide an important insight into the biological defects underlying oxidative damage in patients with COPD. The findings may be of relevance for optimising rehabilitation programmes to overcome muscle damage and exercise intolerance, thereby helping to maximise peripheral components of the syndrome.

\section{MUSCLE OXYGEN TENSION AND LIPID OXIDATION}

It has long been known from studies on high altitude dwellers that there may be an intimate relationship between oxygenation, muscle performance, and oxidative stress. ' The study performed by Koechlin et $a l^{5}$ using molecular probes now carries these observations to a clinically relevant level. Similar to the accumulation of lipofuscin in the muscles of hypoxaemic COPD patients, increased amounts of this lipid degradation product can be found in muscle cells of mountaineers returning from the Himalayas. ${ }^{10}$ This suggests that there is a close relationship between reduced muscular oxygen tension and the accumulation of lipid products in hypoxaemic COPD patients. The unbuffered formation of oxygen radicals with myocellular respiration $^{11}$ is the likely origin of the oxidative damage of lipids with exercise. The production of reactive oxygen species (ROS) is a byproduct of mitochondrial electron transport during increased mitochondrial respiration. ${ }^{9}{ }^{12}$ In hypoxia it can be exaggerated due to increased mitochondrial oxygen consumption resulting from an inequality of oxygen flow and electron transport in the mitochondrial respiratory chain. Heavy exhaustive types of exercise are known to increase lipid peroxidation in the skeletal muscle of healthy subjects. ${ }^{13} 14$ The formation of ROS is thus seen as a regular response of skeletal muscle to increased contractile activity and constitutes an important part of the adaptive signal. ${ }^{15-17}$ Under "physiologically normal" conditions, these ROS are buffered by several antioxidant systems in order to prevent oxidative damage of mitochondrial lipids and lipofuscin accumulation (fig 1). ${ }^{10}$ The study by Koechlin et al now shows that, in hypoxaemic COPD patients, there is an important mismatch in the radical scavenging and redox forces that fails to prevent the damage associated with the increase in ROS during enhanced mitochondrial electron flux. In conjunction with the previous observation that patients with COPD have enhanced lipofuscin accumulation in the vastus lateralis muscle, this suggests a progressive relationship between arterial oxygenation and oxidative muscle damage. ${ }^{18}$

There is evidence that the antioxidant capacity of skeletal muscles in hypoxaemic COPD patients is insufficient to cope with the increasing production of reactive oxygen radicals during exercise at low muscular oxygen tension. For instance, the skeletal muscle fibres of patients with COPD are known to undergo transformation towards a poorly oxygenated type. ${ }^{19} 20$ In addition, it has recently been shown that the total antioxidant capacity of skeletal muscle is markedly higher in patients with COPD than in healthy controls..$^{21}$ Intriguingly, the selective augmentation of glutathione-S-transferase activity in the muscles of patients with $\mathrm{COPD}^{21}$ resembles the permanent augmentation of the Pl-l glutathione-Stransferase isoform in high altitude residents who are protected from lipofuscin accumulation..$^{22}$ An understanding of the protective radical scavenging mechanisms is important as ROS formation and inflammation are related to muscle wasting, a common feature of patients with COPD. $^{6}{ }^{19}$

\section{EXERCISE AS A REMEDY FOR COPD}

These findings on mitochondrial damage in hypoxaemic COPD patients raise questions as to whether the detrimental effects can be overcome by adaptive changes with endurance training. There is reason to believe that repetition of the endurance training stimulus will improve the protective components that reduce the accumulation of oxidative damaged lipids and proteins, the lipofuscin end product of which appears undegradable (fig 1). ${ }^{10}$ For instance, a single bout of exhaustive exercise is known to improve the defence system involved in the scavenging of ROS and possible lipidic mitochondrial targets and DNA repair enzymes within days after recovery from exercise. $^{7324}$ With repetition of the exercise stimulus, a permanent increase in antioxidant activity as well as an improvement in capillary and mitochondrial density are evident in actively recruited muscle..$^{25-29}$ Regular exercise therefore provides an important signal leading to improved oxidative stress defence in skeletal muscle. ${ }^{15-17}$ Importantly, exercise training for 36 months in patients with chronic heart failure is known to enhance the antioxidant capacity in skeletal muscle via 


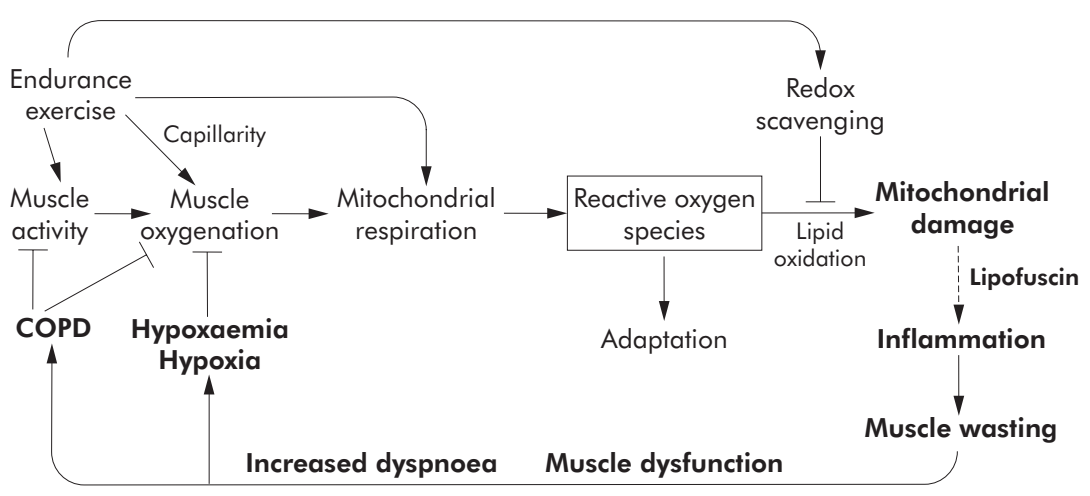

Figure 1 Sequence of events leading to the aggravation of oxidative damage in the mitochondria in hypoxaemic COPD patients and the route of amelioration initiated by endurance training. Pointed and blunt arrows indicate positive and negative effects, respectively, on the indicated process. The muscular changes observed in hypoxaemic COPD patients are shown in bold.

an increase in the activity and gene expression of the radical scavenger enzymes glutathione peroxidase (GPx) and superoxide dismutase (SOD)..$^{28} 3031$ These patients experience significant muscular dysfunction which is similar to that in patients with COPD. The protective effect of exercise on the heart from myocardial ischemia-reperfusion injury is well known. ${ }^{32}$ In the study by Koechlin et al there was no statistically significant increase in GPx and SOD activity 2 days after exercise. In conjunction with previous observations, ${ }^{24}$ this suggests that more intense or repetitive training sessions rather than a single bout of exercise are needed to increase the concentration of radical scavenging systems.

\section{PERSPECTIVES}

Clearly, more research is needed to resolve which exercise training strategy is more suitable for improving the exercise capacity of COPD patients, in view of limited antioxidant defence in the chronically deconditioned locomotory muscles. Studies are needed to determine whether the initial overshoot of oxidative damage in the untrained state should be minimised. These studies should also examine whether moderate training stimuli and supplementation with certain antioxidant nutrients may be better than heavier types of exercise which produce considerably more ROS. ${ }^{13} 31$ Occasional resistance exercise may be an alternative to plain endurance types of exercise. The former kind of training is known to improve other aspects of muscle dysfunction such as mechanical efficiency, ${ }^{33}$ while possibly preserving capillarity. ${ }^{34}$

The study by Koechlin and co-workers provides important findings on muscular limitations in the hypoxaemic subpopulation of COPD patients, which are of relevance for optimal exercise recommendations. The results indicate that the amount and kind of physical activity in this exercise intolerant subpopulation ${ }^{2}$ need to be finely tuned to avoid possible adverse initial muscular defects, and suggest that personalised therapeutic approaches are needed to treat peripheral muscle dysfunction in patients with COPD.

Thorax 2005;60:797-798.

doi: $10.1136 /$ thx.2005.047738

Correspondence to: Dr M Flück, Department of Anatomy, Unit for Functional Anatomy, University of Berne, Baltzerstrasse 2, 3000 Berne 9, Switzerland; flueck@ana.unibe.ch

\section{REFERENCES}

1 Sherk PA, Grossman RF. The chronic obstructive pulmonary disease exacerbation. Clin Chest Med 2000;21:705-21.

2 Serres I, Hayot M, Prefaut C, et al. Skeletal muscle abnormalities in patients with COPD: contribution to exercise intolerance. Med Sci Sports Exerc

3 Morgan MD. Peripheral muscle training in COPD: still much to learn. Thorax 2005;60:359-60.

4 Wewel AR, Jorres RA, Kirsten D. Possibilities and perspectives of home-based exercise training in patients with chronic obstructive pulmonary diseases (in German). Pneumologie 2005;59:328-36.

5 Koechlin C, Maltais F, Saey D, et al. Hypoxaemia enhances peripheral muscle oxidative stress in chronic obstructive pulmonary disease. Thorax 2005;60:834-41.

6 Hesselink RP, Wagenmakers AJ, Drost MR, et al. Lysosomal dysfunction in muscle with special reference to glycogen storage disease type II. Biochim Biophys Acta 2003;1637:164-70.

7 Schrauwen P, Hesselink MK. Oxidative capacity, lipotoxicity, and mitochondrial damage in type 2 diabetes. Diabetes 2004;53:1412-7.

8 Terman A, Brunk UT. Myocyte aging and mitochondrial turnover. Exp Gerontol 2004;39:701-5.

9 Hoppeler $\mathbf{H}$, Vogt $M$, Weibel ER, et al. Response Physiol 2003;88:109-19. lysosomal axis theory of aging: accumulation of damaged mitochondria as a result of imperfect autophagocytosis. Eur J Biochem 2002;269:1996-2002.

11 Leeuwenburgh C, Heinecke JW. Oxidative stress and antioxidants in exercise. Curr Med Chem $2001 ; 8: 829-38$.

12 Pearlstein DP, Ali MH, Mungai PT, et al. Role of mitochondrial oxidant generation in endothelial 1998;30:1019-27. of skeletal muscle mitochondria to hypoxia. Exp

10 Brunk UT, Terman A. The mitochondrial- cell responses to hypoxia. Arterioscler Thromb Vasc Biol 2002;22:566-73.

13 Dekkers JC, van Doornen ப, Kemper HC. The role of antioxidant vitamins and enzymes in the prevention of exercise-induced muscle damage. Sports Med 1996;21:213-38.

14 Baker JS, Bailey DM, Hullin D, et al. Metabolic implications of resistive force selection for oxidative stress and markers of muscle damage during $30 \mathrm{~s}$ of high-intensity exercise. Eur J Appl Physiol 2004:92:321-7.

15 Gomez-Cabrera MC, Borras C, Pallardo FV, et al. Decreasing xanthine oxidase mediated oxidative stress prevents useful cellular adaptations to exercise in rats. J Physiol 2005.

16 Pattwell DM, Jackson MJ. Contraction-induced oxidants as mediators of adaptation and damage in skeletal muscle. Exerc Sport Sci Rev 2004;32:14-8.

17 Radak Z, Chung HY, Goto S. Exercise and hormesis: oxidative stress-related adaptation for successful aging. Biogerontology 2005;6:71-5

18 Allaire J, Maltais F, LeBlanc P, et al. Lipofuscin accumulation in the vastus lateralis muscle in patients with chronic obstructive pulmonary disease. Muscle Nerve 2002;25:383-9.

19 Karlsson J, Diamant B, Folkers K. Exerciselimiting factors in respiratory distress. Respiration 1992;59(Suppl 2):18-23.

20 Jobin J, Maltais F, Doyon JF, et al. Chronic obstructive pulmonary disease: capillarity and fiber-type characteristics of skeletal muscle. J Cardiopulm Rehabil 1998;18:432-7.

21 Gosker HR, Bast A, Haenen GR, et al. Altered antioxidant status in peripheral skeletal muscle of patients with COPD. Respir Med 2005;99:118-25.

22 Gelfi C, De Palma S, Rigamonti M et al. New aspects of altitude adaptation in Tibetans: a proteomic approach. FASEB J 2004;18:612-4.

23 Radak Z, Pucsok J, Mecseki S, et al. Muscle soreness-induced reduction in force generation is accompanied by increased nitric oxide content and DNA damage in human skeletal muscle. Free Radic Biol Med 1999;26:1059-63.

24 Khassaf M, Child RB, McArdle A, et al. Time course of responses of human skeletal muscle to oxidative stress induced by nondamaging exercise. J Appl Physiol 2001;90:1031-5.

25 Fluck M. Exercise-modulated mitochondrial phenotype; sensors and gene regulation. J Muscle Res Cell Motil 2004;25:235-7.

26 Ortenblad N, Madsen K, Djurhuus MS. Antioxidant status and lipid peroxidation after short-term maximal exercise in trained and untrained humans. Am J Physiol 1997;272:R1258-63

27 Wittwer M, Billeter $\mathrm{R}$, Hoppeler $\mathrm{H}$, et al. Regulatory gene expression in skeletal muscle of highly endurance-trained humans. Acta Physiol Scand 2004; 180:217-27.

28 Ennezat PV, Malendowicz SL, Testa M, et al. Physical training in patients with chronic heart failure enhances the expression of genes encoding antioxidative enzymes. J Am Coll Cardiol 2001;38:194-8.

29 Powers SK, Lennon SL. Analysis of cellular responses to free radicals: focus on exercise and skeletal muscle. Proc Nutr Soc 1999;58:1025-33

30 Linke A, Adams V, Schulze PC, et al. Antioxidative effects of exercise training in patients with chronic heart failure: increase in radical scavenger enzyme activity in skeletal muscle. Circulation 2005;111:1763-70.

31 Baneriee AK, Mandal A, Chanda D, et al. Oxidant, antioxidant and physical exercise. Mol Cell Biochem 2003;253:307-12.

32 Powers SK, Quindry J, Hamilton K. Aging exercise, and cardioprotection. Ann NY Acad Sci 2004; 1019:462-70.

33 Richardson RS, Leek BT, Gavin TP, et al. Reduced mechanical efficiency in chronic obstructive pulmonary disease but normal peak $\mathrm{VO}_{2}$ with small muscle mass exercise. Am J Respir Crit Care Med 2004:169:89-96.

34 Luthi JM, Howald H, Claassen H, et al. Structural changes in skeletal muscle tissue with heavyresistance exercise. Int J Sports Med 1986;7:123-7. 


\section{Reviewer selection: author or editor knows best?}

\section{J R Hurst, E C Howard, J A Wedzicha}

\section{Differential behaviour of author and editor suggested reviewers}

T horax is now the second highest ranked respiratory journal and submissions are increasing year on year. ${ }^{1}$ To attract high quality manuscripts, authors must have confidence in our editorial process and we are committed to continuing and improving the transparency, efficiency, and fairness of peer review.

When the current Editors took over the journal in 2003, Thorax changed to online manuscript submission ${ }^{2}$ and, for the first time, authors were formally invited to suggest up to four suitable peer reviewers for their work. Indeed, we encourage authors to suggest reviewers, as set out in our advice to contributors. ${ }^{3}$ Peer review is a vital step in the editorial process, guiding the selection of appropriate papers for publication and providing constructive comments for authors to improve their work. So, what are the benefits of suggesting reviewers (or not) on the editorial process? There is, in fact, little evidence on the behaviour of reviewers suggested by authors in comparison to editors, and we have recently investigated this issue.

We examined the submission of 229 original papers to Thorax, representing a random sample of half of those submitted during the 6 month period from October 2003 to the end of March 2004. Data were collected on the presence, number, and utilisation of author suggested reviewers, together with information regarding the outcome of the submission, subject area, and country of origin. These 229 papers generated 430 reviews, and the behaviour of reviewers suggested by authors and editors was compared. Statistical reviews were excluded.

$57 \%$ of authors suggested reviewers, most commonly providing four names. There were differences in the suggestion of reviewers across country of origin and subject area. Authors from English speaking countries were more likely to suggest reviewers than authors from elsewhere $\quad(58 \% \quad v \quad 34 \%, \quad \mathrm{p}<0.001)$. Regarding subject area, while the two most common topics were COPD and asthma (together accounting for 38\% of submissions), asthma researchers were more likely to suggest reviewers than not, and the reverse was true for COPD.

Manuscripts externally reviewed were more likely to have been written by authors who had suggested reviewers (54\% v 29\%, p<0.001). Perhaps the presence of suggested reviewers encourages external review? This seems unlikely for two reasons. Firstly, on average, from four suggested reviewers only one was actually used, and each paper was reviewed twice. Secondly, if papers with suggested reviewers were being sent out more often because this was easier to achieve, then one would expect a higher proportion of reject decisions by reviewers on these manuscripts. This was not the case. Perhaps, then, the presence of author suggested reviewers is a surrogate marker of manuscript quality?

Of the 430 reviews, $21 \%$ were from author suggested reviewers, with the remainder from reviewers selected by the editors. $75 \%$ of review solicitations were accepted and returned complete, and this did not vary with the source of reviewer. Interestingly, it seems that author suggested reviewers generally return a more favourable response, recommending publication in $64 \%$ of cases compared with $54 \%$ of cases for reviewers selected by editors $(\mathrm{p}=0.138)$. Reflecting this, reviewers suggested by the editors were statistically less likely to return a review discordant with the final editorial decision than author suggested reviewers (25\% $v 41 \%, p=0.010)$. In all cases of discordance between the author suggested reviewer and the final decision, the reviewer had recommended publication. These data are shown in fig 1.

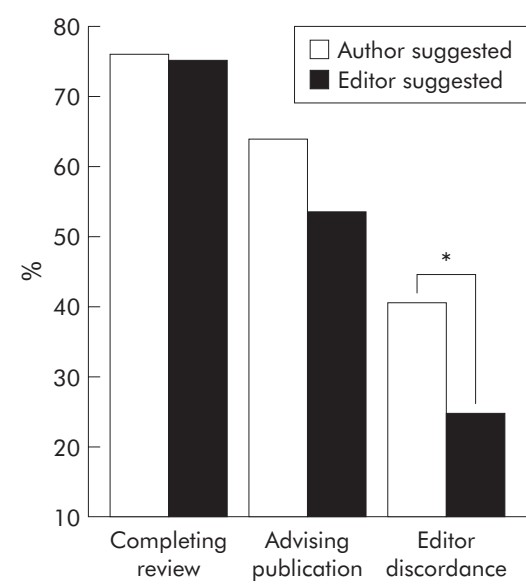

Figure 1 Differential behaviour of reviewers suggested by authors or editors. ${ }^{*} \mathrm{p}=0.01$.

In summary, there are intriguing differences by country of origin and subject area in the proportion of authors who suggest reviewers, and the suggestion of reviewers by authors appears to be a surrogate marker of manuscript quality. The likelihood of a review solicitation being accepted and completed did not differ between reviewers suggested by authors in comparison with editors, but reviewers suggested by authors tended to be more favourable to publication. We trust these resultsthe first to be published on this topicwill interest and inform authors, reviewers, and editors alike. We wish to actively encourage the suggestion of reviewers by authors.

Thorax 2005;60:799.

doi: $10.1136 /$ thx.2005.051870

\section{Authors' affiliations}

J R Hurst, E C Howard, J A Wedzicha, Thorax Editorial Office, BMJ Journals, BMA House, Tavistock Square, London WC1H 9JR, UK

Correspondence to: Professor J A Wedzicha, Thorax Editorial Office, BMJ Journals, BMA House, Tavistock Square, London WC 1H 9JR, UK; J.A.Wedzicha@medsch.ucl.ac.uk

\section{REFERENCES}

1 Wedzicha JA, Johnston SL, Mitchell DM. Thorax annual report: 1 October 2003 to 30 September 2004. Thorax 2004;59:1012-5.

2 Anon. Thorax online submission. Thorax 2002; 57:1004.

3 Anon. The peer review process on Thorax. Available online at http://

thorax.bmijournals.com/misc/ifora/ peerreviewrevs.shtml (accessed 4 May 2005). 